\title{
Corpus y cánones de la oralidad cultural en la educación en Colombia. Una mirada introductoria'
}

\author{
Corpus and Canons of the Cultural Orality in \\ Colombian Education. An Introductory Look
}

Juan Moreno Blanco*

Resumen

Este trabajo establece algunos ejes problemáticos del tratamiento de los textos de la oralidad cultural en el área de lengua materna en la educación en Colombia. Hace una mirada crítica a la situación actual de dicho tratamiento y presenta criterios para establecer corpus textuales de la oralidad cultural en Colombia según el cumplimiento de unos rasgos de canonicidad.

\section{Palabras clave:}

Oralidad cultural, textos orales, agendas educativas; corpus textuales,

rasgos de canonicidad.

\section{Abstract}

This article deals with some problematic issues associated to the textual orality for teaching Spanish as first language in Colombia. It is given a critical look of the current situation. In these terms, it is proposed a wide range of criteria for establishing textual corpus of the cultural orality, according to some canonical features.

\section{Key words:}

Cultural orality, oral texts, educational calendars, textual corpus, canonical features.

Artículo recibido el 15 de febrero de 2008 y aprobado el 12 de mayo de 2008

1 Agradezco los comentarios y aportes que sobre el borrador de este trabajo recibí de Patricia Calonge, del Instituto de Educación y Pedagogía de la Universidad del Valle. Este trabajo es resultado de los seminarios del Grupo de Investigación en Literaturas y Culturas Mitakuye Oyasin.

* Profesor de la Escuela de Estudios Literarios de la Universidad del Valle; Docteur en Études Ibériques et Ibéro-Américaines, Université Michel de Montaigne-Bordeaux III. Áreas de docencia e investigación didáctica de la literatura, oralidad cultural, narrativa colombiana.jmorenofr@yahoo.fr. 
Una de las funciones principales de la formación del canon (literario o no) es asegurar la estabilidad y adaptabilidad de una determinada comunidad de creyentes. Por lo tanto, la comunidad se sitúa a sí misma en relación con una tradición.

Walter Mignolo

En un artículo teórico sobre oralidad fechado en 2002, Carlos Pacheco afirmaba que los estudios de oralidad conforman una línea de investigación que se inició formalmente hace unos 70 años. En ese lapso las fronteras de un dominio y la construcción de un objeto de estudio han ido afinándose desde perspectivas propias de la antropología, la sociolingüística y los estudios literarios. También en Colombia empieza a haber en esa dirección, desde hace más de una década, una bibliografía resultado de trabajos investigativos e iniciativas editoriales que debe ser tenida en cuenta en el momento de desplegar una mirada sobre la cuestión. No obstante, en el contexto colombiano la oralidad como problema no es solo objeto de interés de una agenda teórica o epistemológica sino que, a partir de la puesta en marcha de la Constitución Política de 1991, la oralidad se ha convertido en problema de una agenda política. Esto se debe al hecho de que al reconocer la pluralidad cultural de los colombianos la Constitución deja planteado que todas las culturas del territorio nacional son reconocidas y por ello la cuestión del conocimiento de las culturas cuyos textos no tienen como soporte principal de permanencia la escritura ya no es un simple asunto académico, sino, también, político. Es decir que una agenda política verdaderamente pluralista y democrática debe poner al orden del día una plataforma institucional y académica para que ese reconocimiento constitucional de la creación verbal no letrada se traduzca en praxis de la vida social, cultural y educativa del país.

Si verdaderamente ya no estamos en el país del "Sagrado Corazón de Jesús" ni se estima que Colombia sea el espejo donde se refleja una identidad idiomática, religiosa y cultural unitaria, eso quiere decir que se reconoce la diversidad cultural en la diversidad de tipologías textuales representativas de las diferentes formas de ser-estar en el mundo que en coetaneidad constituyen la realidad civil del país colombiano. De ahí que, en el contexto educativo, debamos replantearnos si los textos literarios son los únicos que hay que estudiar en el área de lengua materna, siendo que en realidad hay una gran diversidad de textos que, sin ser literarios ni escritos, son representativos de la diversidad de culturas en Colombia.

No obstante, la existencia de la Constitución de 1991 no es el único argumento que justifica una agenda política preocupada por el estudio de la oralidad; en realidad, esta agenda está más que justificada históricamente por la existencia de otra agenda política que desde el nacimiento de las repúblicas en América Latina hizo del modelo eurocéntrico de civilización y de la cultura letrada el filtro de lo que fuera reconocido como "verdadera" cultura, desde donde el otro de la modernidad, el que no correspondía con los estándares de la alta cultura, era visto como el bárbaro, el ser cultural infravalorado e invisivilizado por el sujeto letrado, artífice del triunfante proyecto de nación.

Entonces, en el entrecruce de estas dos agendas, la política y la teórico-epistemológica, la oralidad se viene constituyendo o construyendo como objeto y quizás algún día llegue a pensarse que su dominio pueda constituir una disciplina. Por el momento, es urgente que echemos una mirada que nos permita vislumbrar los senderos por donde la oralidad puede empezar a constituirse como objeto de una agenda educativa que se oriente hacia las aspiraciones pluralistas, democráticas y de reconocimiento que necesita la realidad civil del país colombiano.

\section{Los textos de la oralidad no son literatura}

Una de las tendencias teórico-epistemológicas que más han influido en el no conocimiento-reconocimiento de la oralidad como realidad concreta de la cultura es la que pretende que esta es un fenómeno que puede ser integrado al dominio de lo literario. Se presume que la oralidad es un objeto literario, y esto trae como consecuencia, principalmente, que se desnaturaliza al mismo tiempo que se considera en un rango inferior dentro de los géneros literarios. 
Entonces, es necesario empezar por un establecimiento de límites que, al resaltar las diferencias entre oralidad y literatura, nos libre de las amalgamas mistificadoras y jerarquizadoras.

Para diferenciar claramente los textos literarios de los textos de la oralidad (sin tener en cuenta, por el momento, otros rasgos de la oralidad), podemos afirmar que los textos de la oralidad:

No son textos de autor. Esto quiere decir que no hay una persona cívica o un sujeto empírico a quien pueda atribuírsele la autoría de los textos, sino que son anónimos; no son inspiración de un individuo, sino que su origen se vincula con la historia de una sociedad y de una tradición narrativa.

Su existencia como lengua escrita es un accidente. Son textos que han existido desde su inicio como tesoro nemotécnico de una colectividad social. Su naturaleza temática, estilística y estructural está relacionada con esta realidad de la comunicación humana en que la memoria se vierte en la voz para ser actualizada en el frente a frente del emisor y el receptor. No es en absoluto una comunicación diferida. Si un día estos textos de la oralidad son vertidos a la lengua escrita, ello es solo una eventualidad y no podemos creer que la oralidad es solo aquello que la escritura alcanza a reproducir y hacer durar en el soporte escrito.

No son reductibles a un género. En la tradición académica se ha hecho corriente integrar todo texto a una superestructura o pertenencia genérica; con ello se busca lograr unos primeros niveles de inteligibilidad de un texto; sin embargo, las distribuciones genéricas típicas de los estudios literarios no logran abarcar la naturaleza de los textos de la oralidad (por lo demás, estas no fueron hechas para eso). Por tanto, la designación genérica a la que pertenece un texto de la oralidad es una cuestión problemática que aún no ha sido suficientemente estudiada puesto que antes es necesario hacer inteligible las condiciones de emergencia de ese texto como evento vivo de la palabra entre sujetos (performance).
Su inteligibilidad solo es posible dentro del marco de la inteligibilidad de la tradición que las comprende. Un texto oral nunca es una unidad textual aislada, sino que se halla inserta en un tejido cultural. No pueden entenderse su significación global ni su significación parcial si no se conoce la tradición narrativa a la que pertenece. Es decir que un relato, por ejemplo, solo se hace inteligible al lado de otros relatos que compartan sus coordenadas culturales.

Su materialidad textual es modificable. Un texto de la oralidad puede cambiar según el momento y los sujetos comprometidos en su actualización. De hecho, un texto oral nunca es idéntico al mismo texto enunciado en otras situaciones o en otras coordenadas pragmáticas. De ahí que su significancia cultural se halla tanto en su accidentalización como en su fijación.

Por las razones anteriores, y por otras más que por el momento no formularemos, puede afirmarse que hasta el momento no se ha hecho conciencia, en la formulación de los contenidos curriculares de la educación a todos los niveles en Colombia, de la especificidad de los textos de la oralidad y del lugar que ellos deben ocupar en el área de lengua materna. Todo lo más, se habla de mitos, expresión folclórica, leyendas e historias sin llegar nunca a cristalizar un discurso comprensivo de esta realidad verbal que quiere observarse.

\section{La visión excluyente}

Fruto de una larga tradición etnocéntrica que veía en la "alta cultura" la única cultura o la que era modelo de civilización, la oralidad cultural ha sido considerada como un antimodelo de cultura. Ese sesgo valorativo no es explícito ni en las políticas en las teorías ni en los manuales escolares, simplemente desde su discreción nutre las prácticas y los sobreentendidos de nuestra cotidianidad educativa. Puede afirmarse que así como hubo desde siempre en nuestra vida republicana obstáculos infranqueables para reconocer su calidad de ciudadano con plenos derechos al sujeto que no pertenecía a la 
cultura letrada, así mismo existe una resistencia en el establecimiento educativo para el reconocimiento de las tradiciones narrativas de la oralidad. Estas no son "comprensibles" en su especificidad, pues no se ha hecho la reflexión necesaria para visibilizarlas como corpus ni mucho menos para comprender los criterios canónicos que las sociedades vernáculas han aplicado desde siempre para hacerlas suyas $y$ permitirles atravesar las generaciones y las fronteras lingüísticas y culturales.

Veamos cómo en dos manuales del área de lengua castellana se abordan las tradiciones narrativas no letradas'. El manual escolar Español sin fronteras (1989) ubica las tradiciones narrativas no letradas en un apartado o módulo independiente titulado: Literatura aborigen o prehispánica. Nuestros ríos profundos: los indígenas, nuestros antepasados, y se declara el propósito de combatir "la apreciación de desprecio" que hay sobre estas expresiones culturales. No hay ningún fin o propósito educativo que subyazga al contenido del módulo. Bajo el título Habilidades socioafectivas y comunicativas, se dice que:

La tradición oral es la oportunidad más grande que tenemos de reencontrarnos con el pasado y de demostrar respeto por el legado humano de nuestros padres y mayores. Escribir la historia de nuestro pueblo $[\ldots]$ es darle dignidad a la tradición oral y convertirla en un documento histórico (p. 97) [La cursiva es mía].

Así, al introducir los textos orales se les vincula con el pasado, se sitúa en el pretérito su momento de creación y se cae en el estereotipo según el cual la tradición oral es una manifestación anterior a la escritura y a la historia presente.

El manual escolar El Nuevo Port@l del Idioma, castellano y literatura $8 .^{\circ}(2003)$ por su parte ratifica este "lugar cultural" de la oralidad:

Podría parecer curioso que buena parte de la literatura aborigen no haya sido escrita en español,

1 Este aspecto de los manuales escolares está tratado con más detalle en ¿Cómo se abordan las tradiciones narrativas no letradas en la educación básica secundaria en Colombia? Hacia una lectura crítica. Grupo Mitakuye Oyasin. sino en lenguas cuyos nombres prácticamente se desconocen. Más aún, la mayor parte de esta literatura ni siquiera fue escrita, sino que existe en los cantos y las leyendas de los pueblos que habitaron nuestro territorio desde hace miles de años (p. 20) [la cursiva es mía].

Este consenso sobre el "lugar cultural" de la oralidad muestra que en el ámbito educativo, y en las formaciones discursivas que lo enmarcan, este fenómeno de la creación verbal es dejado más allá del margen de lo que se asume como lo cultural propio o, en todo caso, contemporáneo. No obstante, la disposición discursiva que subyace a los manuales escolares no es lo único que debe ser puesto en cuestión; sería necesario que examináramos con atención la política educativa y la teoría que se enseña en nuestras universidades para constatar que la exclusión implícita de la oralidad es una práctica derivada de la monumentalización que se hace de la literatura como exclusiva realidad textual per se representativa de la cultura (Moreno Blanco, 2005 y 2006).

\section{El corpus y los cánones de los textos de la oralidad}

En ejercicio de una visión centralista y nacionalista, desde el siglo XIX, la institución educativa ha construido un corpus de los textos literarios representativos de Colombia o de la cultura colombiana. De tal suerte, los textos culturales que no son literarios ni están registrados en la lengua escrita no hacen parte de este archivo de la "cultura nacional". Por eso debe abandonarse ese tipo de visión para acceder a las vías que nos permitan visibilizar los textos de la oralidad y su anclaje cultural. Lo que está en cuestión es la atribución del carácter "representativo" que puede tener un texto. La verdad es que, a escala nacional, un texto oral no puede ser representativo, pues eso supondría la existencia, en esa escala, de un sujeto cultural e históricamente homogéneo y la ubicuidad de tal texto que podría actualizar su significación sin importar la situación y el lugar.

Sin duda, la mejor manera de encontrar el universo para el cual un texto oral es representativo es realizar la historización de su anclaje social, es decir, 
conocer el aquí y ahora en que el texto "funciona" para unos sujetos concretos. Ese trabajo de historización ha de llevar sin duda a la historia regional y local de las múltiples identidades y territorialidades que componen el país colombiano.

Se trata entonces de abandonar la escala de la "historia patria" y allanar el reconocimiento de los contextos en que la microhistoria, la etnohistoria, el análisis de los vectores migratorios, las yuxtaposición de substratos culturales y lingüísticos pueden servir de preestructura de conocimiento de narraciones (textos) que en la voz y memoria de los sujetos culturales concretos han atravesado las generaciones, las lenguas y siguen alimentando la identidad de comunidades específicas ${ }^{2}$. Entonces ya no estamos hablando de la creación verbal prestigiosa de las élites letradas, sino de la cultura verbal de los sujetos subalternizados, descendientes, la más de las veces, de los vectores históricos amerindios y/o afrocolombianos. Es a esa escala y con conocimiento de causa que sí puede hablarse de representatividad en la medida en que esa riqueza verbal tiene que ver con sujetos sociales concretos.

Solo así podemos poner a prueba categorías que han querido abarcar la creación verbal de la oralidad como la de etnotexto, de Hugo Niño, Literatura alternativa, de Martín Lienhard, etnoliteratura, de Gabriel Ferrer y Yolanda Rodríguez, etc. Son los estudios de caso los que pueden permitir allanar el ámbito de las categorizaciones y clasificaciones que tanta falta, es cierto, nos hacen.

Un ejemplo de estructuración de un corpus canónico, es decir, representativo a escala cultural y social particular puede ser, para ciertas regiones del departamento de La Guajira, el trabajo de selección de textos de la tradición narrativa wayúu hoy día accesibles por medio de libros que han sido el producto del trabajo de investigación de escritores wayúu bilingües, investigadores de estudios literarios y etnólogos3. La aproximación a estos

2 A ese propósito, véase nuestro trabajo de análisis del substrato amerindio de una tradición narrativa en el Magdalena Grande, Moreno Blanco, 2007.

3 Para el caso de los escritores wayúu me refiero al trabajo editorial hecho por Miguel Ángel Jusayú (que publicó cuatro libros bilingües textos implicaría para los docentes que quisieran conocer la tradición narrativa wayúu con miras a su posterior integración al currículo, un proceso de investigación que sin duda los llevaría a buscar esos relatos en la boca de los sujetos wayúu que aún los hacen vivir con su palabra. Estaríamos hablando de un proceder que implica un proyecto capaz de sacar a la institución educativa de la convencional unidireccionalidad en que el conocimiento está en los libros para proponer que el conocimiento puede venir del contacto con la palabra de los sujetos sociales que habitan el contexto.

Es de anotar que el trabajo de reconocimiento del contexto y de los sujetos del contexto seguramente escapa a las competencias del docente del área de lengua materna, de ahí que sea posible plantear desde un principio que un proyecto como este solo puede ser llevado a realización a condición de integrar los objetivos pedagógicos y contenidos curriculares de esta área con los del área de ciencias sociales. Esto haría que la oralidad se convirtiera en el eje transversal de dos disciplinas que buscarían articular la preestructura de conocimiento del contexto con el corpus textual canónico de una tradición vernácula donde lo que pervive y da coherencia a ese tejido narrativo son los ejes temáticos, la lengua, la comunicación no lingüística, es decir, todo lo interiorizado por los individuos pero que proviene de la textura social de la palabra y la cosmovisión.

La cuestión del corpus y del canon de los textos de la oralidad planteada así deja de lado toda pretensión de validez universal o universalista que pudiera llevarnos a postular la existencia de un conocimiento pertinente para todos los contextos. Entonces la canonicidad de los textos queda planteada con relación a una comunidad concreta para la cual ellos son relevantes. De tal suerte, existirían tantos cánones de los textos de la oralidad como tantas comunidades relacionadas con ellos. Tal es

de relatos guajiros) y a Ramón Paz Ipuana (un libro). Es de gran importancia el libro Etnoliteratura wayúu. Estudios críticos y selección de textos, realizado por Gabriel Ferrer y Yolanda Rodríguez (Fondo de publicaciones Universidad del Atlántico, Barranquilla, 1998). En cuanto a trabajos etnográficos, resaltan los dos libros de Michel Perrin: El camino de los indios muertos y Los practicantes del sueño. Un ejemplo de chamanismo. 
la importancia de esta relación entre corpus, canon y comunidad en todo agrupamiento textual que, incluso en el ámbito de lo literario, esta es puesta en evidencia por González Ortega (2002):

Los conceptos de "canon" y "canonización" aplicados a los estudios literarios [...] implican el acto de seleccionar una serie de textos, autores y valoraciones textuales como únicos representantes de la literatura de una comunidad. Los principales aspectos que asocian el canon con la literatura son: a) selección de una lista de textos (corpus), b) el otorgamiento de un valor estético o de una identificación ideológica con unos criterios determinados de selección, c) la cualificación de dichos textos como obras (clásicas) dignas de imitación y de estudio, y d) el poder institucional y político para hacer circular estos textos en la sociedad como obras clásicas de inigualable valor estético.

Evidentemente tendremos que definir para el asunto que nos ocupa cómo entendemos cosas como el valor estético, lo clásico o el poder institucional y político. Además, esto se complica porque, aparte de la relación entre corpus, canon y comunidad, hay que considerar que los textos de la oralidad involucran otra esfera problemática: la de la interacción aural. No hay que olvidar que los relatos orales que son recopilados y registrados en la escritura, al convertirse en textos de comunicación gráfica diferida, adquieren la potencialidad de movilidad del soporte que sin remedio los alejan de su medio sociocultural de origen. Entonces, para el conocimiento de la valía cultural de un texto de la oralidad que ha llegado a nosotros por la vía de lo escrito tendremos que sobreponernos a la discontinuidad histórica que, con su ingreso a la Galaxia Gütenberg, lo alejó del universo de la interacción aural donde la tradición de una comunidad lo hace legible. De ahí que el desentrañamiento del sentido de un texto de la oralidad implique necesariamente la comprensión de la situación en que este acontece como palabra viva.

Entonces la preestructura de conocimiento-reconocimiento de los textos orales debería atender a unos criterios capaces, si no de restaurar el universo de la interacción aural de la que provienen, capaces al menos de hacer visibles los rasgos peritextuales que los definen. A continuación se esbozan algunos de esos rasgos que, tal vez, también pueden convertirse en criterios canónicos que vinculan un corpus textual con una comunidad o una tradición:

1. Su ascendencia: un texto de la oralidad no existe como datura única y aislada, sino que guarda relaciones con otros textos que puestos en red significan más que ellos mismos. Esa mayor significancia del conjunto textual suscita la relación con una matriz histórica y cultural común.

2. Su contemporaneidad: el conocimiento de los textos de la oralidad es pertinente para la comprensión de los rasgos culturales e identitarios de una comunidad que participa con su diferencia en el diálogo presente de la heterogeneidad constitutiva del tejido social. Su presencia constituye la alteridad cultural del proyecto ilustradoletrado.

3. Su representatividad patrimonial: a pesar de su accidentalidad y variabilidad, un corpus de textos de la oralidad siempre delata una coherencia y unidad que lo hace susceptible de ser tomado como patrimonio de un nosotros privativo.

4. Su nexo con la comunicación aural: el estudio de los textos orales puede permitir superar las discontinuidades de diferente orden (históricas, étnicas, lingüísticas, geográficas, sociales) para tratar de aprehender la performance del contador o los contadores de un texto.

5. Su nexo con el territorio: así como todo texto oral está relacionado con una comunidad así también está relacionado con un ámbito geográfico específico que se define, más que por factores empíricos, por las marcas culturales y antropológicas de la sociedad constructora del espacio.

Para finalizar esta mirada introductoria, y con el ánimo de abonar elementos para el debate, propondríamos que estas cuestiones sean circunscritas por el problema político-cultural principalísimo de las políticas de la memoria que mencionan Vich y Zavala (2004: 18):

... la oralidad es una de las instancias mediante las cuales las sociedades construyen un archivo de 
conocimiento destinado a interpretar y negociar el pasado. Actualizadas en situaciones concretas, algunas performances orales funcionan como

\section{Bibliografía}

González Ortega, Nelson. Canon y canonización en la obra literaria, periodística y cinematográfica de García Márquez. Tropelías, 9 y 10, 237-253, 19981999. España [Este texto se encuentra integralmente accesible en Internet].

Grupo Mitakuye Oyasin. (2007). ¿Cómo se abordan las tradiciones narrativas no letradas en la educación básica secundaria en Colombia? Hacia una lectura crítica. En Memorias del II Coloquio Didáctica de la Literatura, Cali, noviembre de 2006, Grupo de Investigación en Literatura y Pedagogía, Escuela de Estudios Literarios-Universidad del Valle.

Mignolo, Walter. (1998). Los cánones y (más allá de) las fronteras culturales (o ¿de quién es el canon del que hablamos?). En: El canon literario, Enric Sullá (comp.), Madrid: Arco/Libros.

Moreno Blanco, Juan. (2005). La competencia literaria en la cartografía de los lineamientos del MEN. Enunciación, Universidad Distrital Francisco José de Caldas, 10, 102-106.

Moreno Blanco, Juan. (2006). Nuestras agendas educativas frente a la crisis del concepto-institución "literatura". En Poligramas, 26, 113-125. Escuela de Estudios Literarios, Universidad del Valle. rituales que escenifican las experiencias vividas y aspiran a intervenir en las políticas de la memoria. \.
Moreno Blanco, Juan. (2007). El chamán amerindio: sustrato temático de los relatos-leyendas del Magdalena Grande [Un estudio de caso de la oralidad regional para su integración a agendas educativas]. En Memorias del II Coloquio Didáctica de la Literatura, Cali, noviembre 2006, Grupo de Investigación en Literatura y Pedagogía, Escuela de Estudios Literarios - Universidad del Valle.

Pacheco, Carlos. (2002), El binarismo oralidad/escritura y los nuevos medios comunicacionales: reflexiones desde el borde del nuevo milenio. En: Cuadernos de literatura, 15, 37-47. Pontificia Universidad Javeriana.

Vich, Víctor; Zavala, Virginia. (2004). Oralidad y poder. Herramientas metodológicas, Bogotá: Norma.

\section{Manuales escolares citados:}

Español sin fronteras 8․, Bogotá: Santillana. 1989.

Nuevo Port@l del idioma, Bogotá: Norma. 2003. 